\title{
Editorial for special issue on high-temperature molten salt chemistry and technology
}

\author{
Shu-qiang Jiao ${ }^{1,2)}$, Ming-yong Wang ${ }^{1)}$, and Wei-li Song ${ }^{2)}$ \\ 1) State Key Laboratory of Advanced Metallurgy, University of Science and Technology Beijing, Beijing 100083, China \\ 2) Institute of Advanced Structure Technology, Beijing Institute of Technology, Beijing 100081, China
}

High-temperature molten salt consisting of metal cation and non-metal anion is a promising media to break the limits of aqueous solution due to high conductivity, wide electrochemical window, rapid mass transfer, high solubility to reactants, low vapor pressure, etc. In the past two hundred years, high-temperature molten salt chemistry and technology attract widely interests. Particularly, molten salt electrolysis as an indispensable metallurgy technology has been applied industrially for metal extraction of $\mathrm{Al}$, rare earth, and alkali/alkaline-earth metals. It is well known that industrial aluminum electrolysis was invented by Hall and Heroult in the end of the 19th century. It is a milestone and promotes the change of $\mathrm{Al}$ from noble metal to bulk metal. At present, the yield of $\mathrm{Al}$ has reached to 62 millions tons all over the world in 2019. High-temperature molten salt chemistry and technology has brought a revolutionary advancement to human life and infrastructure construction.

Since the 21st century, the application and investigation of molten salt chemistry and technology were further extended. Various novel electrolysis methods, such as FFC, OS, USTB etc., were proposed for the extraction of high melting point metals (i.e., Ti, V, Si etc.). Besides traditional metallurgy, high-temperature molten salts chemistry and technology were also used for the preparation of functional materials and the treatment of secondary resources and energy storage. High-temperature molten salt chemistry and technology have become an interdisciplinary including chemistry, physics, metallurgy, energy, environmental, and so on. It is expected to inject vitality to the development of traditional industries and will become a research hotspot.

It is our honor as Guest Editors of the journal International Journal of Minerals, Metallurgy and Materials to organize the special issue on the topic of "High-temperature molten salt chemistry and technology." It includes thirteen novel research articles and three comprehensive reviews. All pa- pers were mainly focused on advanced electrometallurgy, recovery and utilization of secondary resources, and the preparation of functional materials and rechargeable batteries in molten salts. The original works will provide insight to understand the recent development and frontiers of high-temperature molten salt chemistry and technology.

Electrometallurgy in high-temperature molten salts still receives the largest attentions. Particularly, the extraction of refractory metals and the separation of rare earth were mainly studied. FFC Cambridge Process for Ti extraction by the electrodeoxidation of solid $\mathrm{TiO}_{2}$ cathode in $\mathrm{CaCl}_{2}$ molten salts was proposed in December 1999. Generally, calcium titanate was considered as an inevitable intermediate. Wang et al. [1] used calcium titanate as solid cathode and the electrodeoxidation behavior was investigated. It was found that the reduction rate of $\mathrm{Ca}_{3} \mathrm{Ti}_{2} \mathrm{O}_{7}$ was larger than that of $\mathrm{CaTiO}_{3}$ due to more "diffusion channels" which was created by the release of $\mathrm{Ca}^{2+}$. Meanwhile, a new method was also proposed to convert and recycle excess $\mathrm{CaO}$ from $\mathrm{Ca}_{3} \mathrm{Ti}_{2} \mathrm{O}_{7}$ precursor. In addition, metal $\mathrm{Cr}$ was also successfully obtained by the electrodeoxidation of solid $\mathrm{Cr}_{2} \mathrm{O}_{3}$ cathode based on solid oxide membrane-assisted FFC Cambridge Process [2]. It was found that large porosity, small particle size, and high voltage can accelerate the reduction rate. The reduction of $\mathrm{Cr}_{2} \mathrm{O}_{3}$ proceeded in a two-step process, i.e. $\mathrm{Cr}_{2} \mathrm{O}_{3}$ to $\mathrm{CrO}$, and then to $\mathrm{Cr}$. Compared with aqueous electrolytes, high-temperature molten salts may lead to unwanted electrode-electrolyte interactions. Chen [3], one of inventors of FFC Cambridge Process, provided a profound review focusing on various interactions between molten salts and solid cathodes. Typical perovskitisation, non-wetting of molten salts on metals, carbon contamination to products, and the formation of oxychlorides and calcium intermetallic compounds were discussed in detail. The proper understanding to various interactions was crucial to develop the optimum and feasible

Corresponding author: Shu-qiang Jiao E-mail: sjiao@ustb.edu.cn 
approaches for metal extraction.

OS process is another important molten salt electrochemical technology for Ti extraction. An upgraded OS process was proposed by Ahmadi et al. [4]. TiN or $\mathrm{TiO}_{x} \mathrm{C}_{y} \mathrm{~N}_{z}$ was firstly synthesized by simultaneous carbothermal reduction and nitridation of ilmenite $\left(\mathrm{FeTiO}_{3}\right)$, and then transformed to a high-purity $\mathrm{TiS}_{2}$ by $\mathrm{S}_{2}$ gas. Ti powders were further prepared by OS process from $\mathrm{TiS}_{2}$ and the quality was much better than that by conventional OS process from $\mathrm{TiO}_{2}$.

It is well known that metal oxides or sulfides were usually insoluble and can only be electroreduced to metal in solid phase. Generally, the reduction rate and current efficiency are low. Soluble metal fluorides were beneficial to be reduced to metals with high purity. Wu et al. [5] prepared dendritic metal $\mathrm{Hf}$ in a $\mathrm{NaCl}-\mathrm{KCl}-\mathrm{NaF}-\mathrm{K}_{2} \mathrm{HfF}_{6}$ molten salt. It was found that the reduction mechanism of $\mathrm{Hf}$ (IV) depended on $\mathrm{NaF}$ concentration. One-step reduction process can be achieved and disproportionation reaction between Hf metal and Hf complex ions can be effectively inhibited at high $\mathrm{NaF}$ concentrations $\left(17.39<\right.$ molar ratio of $\left.\left[\mathrm{F}^{-} / \mathrm{Hf}^{4+}\right]<23.27\right)$.

Rare earth was usually extracted by molten salt electrolysis. Sun et al. [6] separated $\mathrm{Nd}$ from $\mathrm{Cu}_{6} \mathrm{Nd}$ alloy as anode by electrorefining in $\mathrm{NaCl}-\mathrm{KCl}-0.5 \mathrm{~mol} \% \mathrm{NdCl}_{3}$ molten salt. On Mo cathode, $\mathrm{Nd}$ without any $\mathrm{Cu}$ was electrodeposited. However, on Fe cathode, $\mathrm{NdFe}$ alloy with the ratio of 1:1 was obtained. On the other hand, the separation of rare earth from fission products was a key problem for the reprocessing of spent nuclear fuel. The electrodeposition of rare earth on inert and reactive cathodes was widely studied. Yin et al. [7] compared the electrochemical and underpotential deposition behavior of samarium $(\mathrm{Sm})$ on various reactive metal electrodes $(\mathrm{M})$ in $\mathrm{LiCl}-\mathrm{KCl}$ molten salt. It was confirmed that Sm metal can not be electrodeposited on inert electrode, but Sm-M alloys were obtained by underpotential deposition due to the depolarization effect. The depolarization values of reactive metals were arranged in the following order: $\mathrm{Zn}>\mathrm{Al}>$ $\mathrm{Ni}>\mathrm{Cu}$.

For both the extraction of refractory metals and the separation of rare earth by molten salt electrochemical technology, the electroreduction of metals with high valence usually proceeded by a multi-step electron-transfer process on conventional solid cathode, which will lead to large polarization degree. Liquid metal cathodes attracted wide interests due to the depolarization effect and direct preparation of alloys. Jiao et al. [8] discussed the properties of liquid metal cathodes and their selection rules in a comprehensive review. The development of liquid metal cathodes for molten salt electrolysis, specifically the extraction of $\mathrm{Ti}$ and the separation of rare earth, was summarized. An attractive and promising strategy for the preparation of liquid Ti alloys via molten oxide electrolysis on liquid metal cathodes was also reviewed.

Molten salt electrolysis was also an environmentally friendly method for the recovery and utilization of secondary resources, such as $\mathrm{CO}_{2}$ and metal solid wastes. Hu et al. [9] transformed $\mathrm{CO}_{2}$ into S-doped carbon nano-fibers (CNFs) based on the capture of $\mathrm{CO}_{2}$ by molten salts and subsequent electrochemical reduction. It was found that the catalysts (such as $\mathrm{NiO}, \mathrm{Co}_{2} \mathrm{O}_{3}$, and $\mathrm{Fe}_{2} \mathrm{O}_{3}$ ) and cathode materials can change the diameter distribution and morphology of CNFs. Liu et al. [10] provided a novel method to effectively separate $\mathrm{Fe}$ and $\mathrm{Mn}$ from simulated chlorinated vanadium slag by molten salt electrolysis. One-step electroreduction of $\mathrm{Fe}^{2+}$ and $\mathrm{Mn}^{2+}$ in the form of $\mathrm{FeCl}_{2}$ and $\mathrm{MnCl}_{2}$ in $\mathrm{NaCl}-\mathrm{KCl}$ molten salt was confirmed. Fe was firstly recovered at low cell voltage, and then $\mathrm{Mn}$ at high cell voltage. Xi et al. [11] presented a good review about application of molten salts and progress of molten salt electrolysis in secondary metal resource recovery. The applications of molten salts in chemistry, electrochemistry, and energy and thermal storage were elaborated. The research progresses to metal recovery by molten salt electrolysis from various wastes, such as magnet scrap, nuclear waste, and cemented carbide scrap, were discussed comprehensively.

In view of the distinctive physicochemical properties, high-temperature molten salts were also good medium for the preparation of advanced materials. Tian et al. [12] proposed a feasible method for one-step $\mathrm{N}$-doping to carbon paper by molten salt electrolysis in $\mathrm{LiCl}-\mathrm{KCl}-\mathrm{Li}_{3} \mathrm{~N}$ molten salt. $\mathrm{N}$ content in carbon paper was up to $13 \mathrm{wt} \%$. N-doping carbon paper was expected to be a potential positive material for Alion battery. Fe-Ni36 Invar alloy was prepared via one-step electrolysis of mixed oxides in molten carbonates by Dou et al. [13]. The method may be an energy-effective and lowcarbon emission strategy to prepare various Fe-based alloys. Zhou et al. [14] fabricated $\mathrm{Ta}_{3} \mathrm{~N}_{5} / \mathrm{TaOH}$ composites by pyrolysis of $\mathrm{Ta}_{2} \mathrm{O}_{5} /$ melamine mixture in molten chlorides. It was found that $\mathrm{TaON}$ nanoparticles were closed anchored to $\mathrm{Ta}_{3} \mathrm{~N}_{5}$ nanorods. The composites with heterojunction exhibited an enhanced photocatalytic activity for degradation of methylene blue.

Rechargeable batteries with molten salt electrolyte may become a promising direction in future. Wang et al. [15] used $\mathrm{AlCl}_{3}-\mathrm{NaCl}$ inorganic molten salt as electrolyte of Al-ion battery. It was confirmed that flake graphite stacked with graphene nanosheets as positive electrode delivered a high capacity of $\sim 219 \mathrm{mAh} \cdot \mathrm{g}^{-1}$ over 1200 cycles at $5 \mathrm{~A} \cdot \mathrm{g}^{-1}$ and the Coulombic efficiency was about 94.1\%. Recently, liquid metal batteries have attracted wide attention and molten salts were indispensable electrolyte. Ning et al. [16] designed a $\mathrm{Ca}\left|\mathrm{LiCl}-\mathrm{NaCl}-\mathrm{CaCl}_{2}\right| \mathrm{Ca}-\mathrm{Pb}$ battery. The dissolution of $\mathrm{Ca}$ in electrolyte was successfully suppressed by multi-cation electrolyte and alloy electrode. High discharge voltage of 0.6 $\mathrm{V}$ and coulombic efficiency of $99 \%$ were obtained.

The special issue summarized some of the latest advancement in high-temperature molten salt chemistry and technology, which will provide helps for readers to explore new re- 
search directions in the interdisciplinary fields of metallurgy, materials, environment, energy, and so on. So, we are appreciated to all authors for their innovative works and all reviewers for their helpful comments. We sincerely thank the Editorial Team of IJMMM for their hard work to get the publication of special issue.

\section{References}

[1] D. Wang, S. Pang, C.Y. Zhou, Y. Peng, Z. Wang, and X.Z. Gong, Improve titanate reduction by electro-deoxidation of $\mathrm{Ca}_{3} \mathrm{Ti}_{2} \mathrm{O}_{7}$ precursor in molten $\mathrm{CaCl}_{2}$, Int. J. Miner. Metall. Mater., 27(2020), No. 12, p. 1618.

[2] B. Wang, C.Y. Chen, J.Q. Li, L.Z. Wang, Y.P. Lan, and S.Y. Wang, Solid oxide membrane-assisted electrolytic reduction of $\mathrm{Cr}_{2} \mathrm{O}_{3}$ in molten $\mathrm{CaCl}_{2}$, Int. J. Miner. Metall. Mater., 27(2020), No. 12 , p. 1626

[3] G.Z. Chen, Interactions of molten salts with cathode products in the FFC cambridge process, Int. J. Miner. Metall. Mater., 27(2020), No. 12, p. 1572.

[4] E. Ahmadi, R.O. Suzuki, T. Kikuchi, T. Kaneko, and Y. Yashima, Towards a sustainable technology for production of extrapure $\mathrm{Ti}$ metal: electrolysis of sulfurized $\mathrm{Ti}(\mathrm{C}, \mathrm{N})$ in molten $\mathrm{CaCl}_{2}$, Int. J. Miner. Metall. Mater., 27(2020), No. 12, p. 1635.

[5] Y.K. Wu, G.Q. Yan, S. Chen, and L.J. Wang, Electrochemistry of $\mathrm{Hf}(\mathrm{IV})$ in $\mathrm{NaCl}-\mathrm{KCl}-\mathrm{NaF}-\mathrm{K}_{2} \mathrm{HfF}_{6}$ molten salts, Int. $J$ Miner. Metall. Mater., 27(2020), No. 12, p. 1644.

[6] C.T. Sun, Q. Xu, Y.P. Xiao, and Y.X. Yang, Electrochemical deposition of $\mathrm{Nd}$ and $\mathrm{Nd}-\mathrm{Fe}$ alloy from $\mathrm{Cu}_{6} \mathrm{Nd}$ alloy in $\mathrm{NaCl}-\mathrm{KCl}-\mathrm{NdCl}_{3}$ melt, Int. J. Miner. Metall. Mater., 27(2020), No. 12 , p. 1650

[7] T.Q. Yin, L. Chen, Y. Xue, Y.H. Zheng, X.P. Wang, Y.D. Yan, M.L. Zhang, G.L. Wang, F. Gao, and M. Qiu, Electrochemical behavior and underpotential deposition of samarium on reactive electrodes $(\mathrm{Al}, \mathrm{Ni}, \mathrm{Cu}$ and $\mathrm{Zn})$ in $\mathrm{LiCl}-\mathrm{KCl}$ melt, Int. J. Miner. Metall. Mater., 27(2020), No. 12, p. 1657.

[8] S.Q. Jiao, H.D. Jiao, W.L. Song, M.Y. Wang, and J. G. Tu, A review on liquid metals as cathodes for molten salt/oxide electrolysis, Int. J. Miner. Metall. Mater., 27(2020), No. 12, p. 1588 .

[9] M.J. Hu, M.Z. Yin, L.W. Hu, P.J. Liu, S. Wang, and J.B. Ge, High value utilization of $\mathrm{CO}_{2}$ to synthesize sulfur-doped carbon nanofibers with excellent capacitive performance, Int. $J$. Miner. Metall. Mater., 27(2020), No. 12, p. 1666.

[10] S.Y. Liu, Y.L. Zhen, X.B. He, L.J. Wang, and K.C. Chou, Recovery and separation of $\mathrm{Fe}$ and $\mathrm{Mn}$ from simulated chlorinated vanadium slag by molten salt electrolysis, Int. J. Miner. Metall. Mater., 27(2020), No. 12, p. 1678.

[11] X.L. Xi, M. Feng, L.W. Zhang, and Z.R. Nie, Applications of molten salt and progress of molten salt electrolysis in secondary metal resource recovery, Int. J. Miner. Metall. Mater.
27(2020), No. 12, p. 1599.

[12] D.H. Tian, Z.C. Han, M.Y. Wang, and S.Q. Jiao, Direct electrochemical N-doping to carbon paper in Molten $\mathrm{LiCl}-\mathrm{KCl}-\mathrm{Li}_{3} \mathrm{~N}$, Int. J. Miner. Metall. Mater., 27(2020), No. 12, p. 1687.

[13] Y.P. Dou, D.Y. Tang, H.Y. Yin, and D.H. Wang, Electrochemical preparation of the $\mathrm{Fe}-\mathrm{Ni} 36$ Invar alloy from a mixed oxides precursor in molten carbonates, Int. J. Miner. Metall. Mater., 27(2020), No. 12, p. 1695.

[14] J. Zhou, D.D. Nie, X.B. Jin, and W. Xiao, Controllable nitridation of $\mathrm{Ta}_{2} \mathrm{O}_{5}$ in molten salts for enhanced photocatalysis, Int. $J$. Miner. Metall. Mater., 27(2020), No. 12, p. 1703.

[15] J.X. Wang, J.G. Tu, H.D. Jiao, and H.M. Zhu, Nanosheetstacked flake graphite for high-performance $\mathrm{Al}$ storage in inorganic molten $\mathrm{AlCl}_{3}-\mathrm{NaCl}$ salt, Int. J. Miner. Metall. Mater., 27(2020), No. 12, p. 1711

[16] X.H. Ning, C.Z. Liao, and G.Q. Li, Electrochemical properties of $\mathrm{Ca}-\mathrm{Pb}$ electrode for calcium-based liquid metal batteries, Int. J. Miner. Metall. Mater., 27(2020), No. 12, p. 1723.

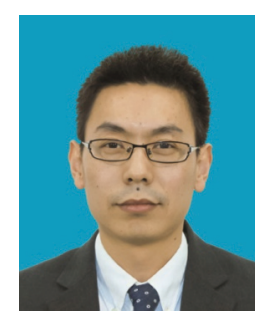

Shu-qiang Jiao is a professor at the University of Science and Technology Beijing, China since 2009. He has published over 200 papers. He invented a novel high-temperature molten salt electrolysis method for Ti extraction, named USTB process. He proposed a rechargeable $\mathrm{Al}-\mathrm{C}$ secondary battery with the electrolyte of ionic liquid/AlCl3 or inorganic molten salts.

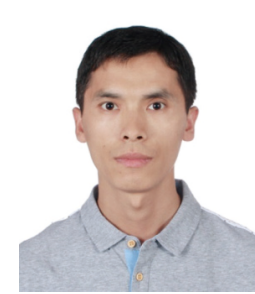

Ming-yong Wang is a professor at the University of Science and Technology Beijing, China. He has published over 110 papers. His research interests focused on electrometallurgy in both high-temperature molten salt and aqueous solution. He proposed a novel soluble oxysalt electrolysis (SOSE) to metal/oxides in high-temperature molten salts.

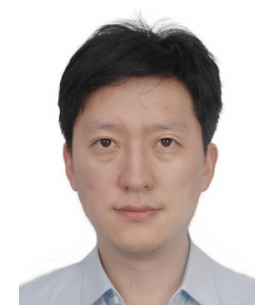

Wei-li Song is currently an associate professor in Institute of Advanced Structure Technology at Beijing Institute of Technology (BIT). His research focuses on high-value utilization of carbon resource using molten salts as well as electrode kinetics for electrolysis and electrochemical processes. He holds international peer-reviewed publications more than 100 . 